\title{
A Brief Analysis of AI Curricula Construction and Development Orientation from the Perspective of Innovation and Entrepreneurship Education
}

\author{
Siqin Tan \\ Shanghai Publishing and Printing College, Shanghai, China \\ Email:174596142@qq.com
}

How to cite this paper: Tan, S. Q. (2020). A Brief Analysis of AI Curricula Construction and Development Orientation from the Perspective of Innovation and Entrepreneurship Education. Creative Education, $11,1866-1872$.

https://doi.org/10.4236/ce.2020.1110136

Received: September 8, 2020

Accepted: October 11, 2020

Published: October 14, 2020

Copyright $\odot 2020$ by author(s) and Scientific Research Publishing Inc. This work is licensed under the Creative Commons Attribution International License (CC BY 4.0).

http://creativecommons.org/licenses/by/4.0/

\begin{abstract}
The advent and booming development of the artificial intelligence has opened up new fields and opportunities for innovation and entrepreneurship education in Institutions of higher learning. By March 2018, 32 colleges and universities had set up Institute of artificial intelligence. This paper based on the analysis of the importance of incorporating entrepreneurship education into AI curriculum puts forward and elaborates the methods and paths of integrating innovation and entrepreneurship education into AI curriculum.
\end{abstract}

\section{Keywords}

Innovation and Entrepreneurship Education Current Situation, Artificial Intelligence, Curriculum Construction

\section{Introduction}

As a strategic industry with high priority for the state, $\mathrm{AI}$ is a symbol of this era, a new and hot specialty in China, as well as a set of related courses. The arrival of AI era enables new areas for innovation and entrepreneurship-oriented education in colleges, and brings new development opportunities for the colleges.

Artificial Intelligence (AI) has become a national strategy. In order to respond the call of "Mass entrepreneurship and innovation", building up innovation and entrepreneurship-oriented colleges is an important measure for colleges to promote innovation and entrepreneurship-oriented educational reform. The 21st century is an era in which AI become prosperous, and the ways of people's study, living and work have been changed completely. As an emerging develop- 
ing country, China always focuses on innovation education and the cultivation of talents of innovation and entrepreneurship. We should endeavor to build new teaching forms for innovation and entrepreneurship-oriented education, establish a new platform for the practices of innovation and entrepreneurship-oriented education, improve the service level of innovation and entrepreneurship-oriented education, develop a new system for operating innovation and entrepreneurshiporiented education, and enable high-standard entrepreneurship and employment of the graduates. The R \& D of AI technology and cultivation of AI talents oriented by innovation and entrepreneurship are the inexhaustible driving force for the development of AI.

\section{The Arrival of AI Era and the Build-Up of AI Curriculum}

\subsection{The Arrival of AI Era and the Need of the Time}

Driving by technological and industrial revolution, human society has been changing due to technological innovation. Old societies were destructed and rebuilt. The arrival of AI era changes the way of people's living. In AI era, only nations which have occupied the commanding heights of the development of economy and technology can be undefeatable in the competition in the future. As the second large economic entity, China will surely be unwilling to yield to others. "Mass entrepreneurship and innovation" is adopted as the driving force for the development of AI. In the notice "Action plan for AI innovation in colleges and universities" issued by the Ministry of Education in 2018, colleges and universities are required to "improve AI talents cultivation system" and "enhance the collaborative innovation and strategic research for AI" (Kong \& Feng, 2017). AI specialties and curricula is therefore constructed quickly, and become hot among the students in 2018.

\subsection{Development Prospect of the Construction of AI Specialties and Curricula}

New technologies provide brand new perspectives for developing education. Although no consensus is reached about the essence and meanings of AI at present, AI is regarded as a subject. The Ministry of Education mentioned explicitly that "tier 1 specialties, undergraduate courses and talents" should be focused on in the construction of AI specialties (Zhou, Gao, \& Xu, 2018). AI specialties and schools are on the agenda of colleges and universities across China. By the end of March 2018, there were 32 colleges and universities which have AI schools (The Ministry of Education, 2018). According to the requirements of the Ministry of Education, colleges and universities should research on the talent cultivation mode "AI + X" based on the features of AI specialties. For curricula construction which is an important aspect of specialties construction, the Ministry of Education's guideline is "to promote the construction of AI teaching materials and on-line open courses, especially main courses such as AI basic, machine learning, neural network, pattern recognition, computer vision, knowledge 
engineering and natural language processing." (Xie, 2017). No doubt, the substantial promotion of the Ministry of Education enables substantial development of the construction of specialties and curricula of AI education in colleges and universities. We can see that in the plan of education sector, the construction of specialties and curricula is the key point in higher education in the future. In other word, the prospect of AI education is bright.

\subsection{Goals and Significance of the Construction of AI Curricula}

In AI era, AI is widely used in many aspects. That's helpful for the development of the economy and society. However, it's impossible and infeasible to cultivate a lot of talents who master new AI technologies in a short time. It's a task which needs the whole society to be involved in. Higher educational institutions must make their own contribution for it. With the development plan and a large amount of capital provided by the state, higher educational institutions should include combine the construction of AI specialties and related curricula into the current development concept of higher education. Technological innovation and construction of specialties should also be closely connected to the development prospect of $\mathrm{AI}$, in order to bring the teaching for $\mathrm{AI}$ specialties into a new and higher stage. "In AI era, facing the strategic assumptions and choices from new technology revolution, new industry revolution and new economic mode, we should focus on cultivate new-type engineering and technology talents with thinking, attitude, skills and knowledge of innovation and entrepreneurship, so as to promote the development of technology and economy in the country." (Anonym, 2015). Therefore, in the process of cultivation and exploitation of AI human sources, the higher education institutions should attach enough importance to AI specialties and related courses, and combine AI with other specialties and domains, in order to promote the development and progress of AI technologies with innovations.

\section{The Significance of including "Mass Entrepreneurship and Innovation" and Entrepreneurship Education into AI Curricula}

As a brand new domain, $\mathrm{AI}$ is a kind of technological specialty. The engineering characteristics of this specialty is very obvious. Along with the development of AI and information technologies, people's living, work and study will changed accordingly. The main reason why many developed countries were replaced by emerging countries is that those countries didn't invest continuously on information technology and AI. As the largest developing country in this world, leading by Communist Party of China, Chinese people, for realizing the rejuvenation of Chinese nation, must pay close attention to entrepreneurship and innovation in AI era. For that reason, Mr. Li Keqiang firstly put forward the call of "Mass entrepreneurship and innovation" in Summer Davos in September 2014 (Anonym, 2019). After that, a trend of "Mass entrepreneurship and innovation" 
emerged in China. Innovation and entrepreneurship education is paid more and more attentions, and developed remarkably. Thanks to this trend, since 2015, entrepreneurship education schools and courses have been established in colleges and universities across China. Most of the colleges and universities have enough full-time or part-time teachers for entrepreneurship education. At the same time, integrating entrepreneurship concepts and spirits into all specialties becomes an important topic for teaching reform in colleges and universities across China. As a new branch of science, although AI specialty and related courses came out late, entrepreneurship concepts had been included in them. However, from the perspective of demand for talents of entrepreneurship education in AI era, the level of innovation and entrepreneurship in China falls behind developed countries, which is a problem needing to be solved as soon as possible. Therefore, "Action plan for AI innovation in colleges and universities" issued by the Ministry of Education explicitly requests "support to innovation and entrepreneurship. National university science parks and innovation and entrepreneurship bases are encouraged to carry out innovation and entrepreneurship projects about AI." (Wang \& Tao, 2018).

\section{Ways and Paths for Integrating Innovation and Entrepreneurship Education into AI Courses}

\subsection{The Teachers for AI Courses must have Innovation and Entrepreneurship Concepts}

Teacher is an important factor for the all-around development of the students. As an important medium for spreading knowledge, teachers should have innovation and entrepreneurship consciousness and experiences, and teach with innovation and entrepreneurship concepts. During the teaching process of AI courses, innovation and entrepreneurship concepts should be included into "classroom teaching methods in order to highlight the competence, skills and knowledge of innovative teachers". Thus, for the election and cultivation of teachers for AI courses, excepting professional knowledge, innovation and entrepreneurship concepts, knowledge and experience are also important in training the teachers. Besides improving professional teaching and research level, The teachers should enhance their innovation and entrepreneurship consciousness, accumulate innovation and entrepreneurship experience, and include them into teaching for AI courses.

We should improve the curriculum system of innovation and entrepreneurship. The improvement of curriculum system is the theoretical basis of innovation and entrepreneurship education. Therefore, both teaching content and teaching methods should be fully advocated, such as reverse classroom, simulated entrepreneurship and other forms. Teachers should pay attention to the comprehensiveness of knowledge and ability, guide students' innovative thinking mode, and make students feel the whole process of "knowledge practice entrepreneurship" with the help of modern teaching platform and professional 
skill training platform. Joint venture enterprises to build a college students' employment and entrepreneurship base, to provide real scenes for college students' hands-on practice.

We should focus on the construction of innovation and entrepreneurship teaching team. We should improve the teaching level of innovation and entrepreneurship as a whole, strengthen the research level of teachers in innovation and entrepreneurship, and build a special innovation and entrepreneurship teaching team. The second is to establish a part-time expert database of innovation and entrepreneurship education, with enterprise executives and successful entrepreneurs as the main part-time expert teaching team. Through their entrepreneurial process to guide college students' innovation and entrepreneurship ideas, and provide practical guidance for students. Finally, we should establish a scientific education and teaching evaluation system to promote the healthy development of innovation and entrepreneurship education. First, the content of evaluation should be scientific and accurate, and scientific evaluation standards should be formulated for key parts such as teaching system and classroom teaching; second, in terms of evaluation subjects, all social forces, schools and students themselves should participate to make the evaluation system more objective and universal; third, in terms of evaluation indicators, scientific positioning should be made according to different regions and fields; fourth, in terms of evaluation effect, the evaluation should be carried out according to different regions and fields, In order to achieve the effect of positive motivation, we should reasonably use the credit of the second classroom, the credit of science and technology practice or the additional score of comprehensive evaluation.

\subsection{Definite Requirement that Innovation and Entrepreneurship Contents Should Be Attached with Enough Importance Should Be Given}

As an important part of higher education, college students' innovation and entrepreneurship education is not only the key to improve students' future development competitiveness, but also a strong guarantee to further deepen and improve the teaching structure of higher education.

In the era of "Mass entrepreneurship and innovation", it's an inevitable requirement to innovation, entrepreneurship and cultivating talents with entrepreneurship spirits. In AI era, transformation to systematic and specialized entrepreneurship education (Liu, 2018) is a priority among priorities. The construction and development of AI curricula requires enhancement of innovation and entrepreneurship education. Colleges and universities must actively promote the research of AI, invest a great many of human and material resources for related activities, encourage professional teachers and researchers to expand the research range and depth, and implement interdisciplinary researches and analysis of all kinds of problems. Proper conditions for close integration of AI and entrepreneurship education should be provided. The experience of developed countries for the combination of AI and innovation and entrepreneurship 
education could be learned, including experience for both successes and failures.

The traditional innovation and entrepreneurship education mode is lack of interest and pertinence, so it is difficult to stimulate students' interest in learning. Therefore, to break the traditional innovation and entrepreneurship education mode, in the era of artificial intelligence, teachers of innovation and entrepreneurship education can completely break the traditional innovation and entrepreneurship education mode with the advantages of artificial intelligence technology, and help students establish a correct concept of entrepreneurship, so that entrepreneurship activities will not face excessive investment risk because of their high aspirations, The opportunity to start a business is too conservative to lose. Due to the lack of social experience, college students will inevitably face a variety of problems in the process of innovation and entrepreneurship. In the process of innovation and entrepreneurship education, teachers should reasonably choose education methods. They should not only pay attention to the cultivation of students' innovation and entrepreneurship ability, but also strengthen the guidance of students' thinking, so as to promote the overall development of students and expand the influence of innovation and entrepreneurship education, And let more students benefit from it.

\subsection{Establishing Well-Equipped Training and Practice Bases}

Colleges and Universities need urgently a breakthrough in educational and teaching reform for resolving the structural problem that traditional education system is disjointed with the practices. The construction of AI curricula includes both constructions of theoretical courses and practice courses. To a certain extent, the construction of practice courses is more important than theoretical courses. Therefore, colleges and universities should build well-equipped training and practice bases and offer more opportunities for the students to practice. At the same time, innovation and entrepreneurship education should be enhanced in AI practice courses. Except having the students understand professional AI knowledge, we should also have the student realize that $\mathrm{AI}$ is not just a voguish word, but a technology which can change everything if it's widely used in production and society. Therefore, based on the progress of AI curricula construction, colleges and universities should establish well-equipped training and practice bases for innovation and entrepreneurship education with consideration of the actual situations, in order to provide a good practice environment for the students of AI specialties.

\section{Conflicts of Interest}

The author declares no conflicts of interest regarding the publication of this paper.

\section{References}

Anonym (2015). Interpretation to Li Keqiang’s Call of “Mass Entrepreneurship and In- 
novation": "Mass" Is the Key Word. Economic Daily.

Anonym (2019). 32 Institutions of Higher Learning in China Have Established AI Specialties. https://tech.hqew.com/fangan 2019144

Kong, L. Q., \& Feng, Y. (2017). Development Difficulties and Transformation of Paths of Entrepreneurship Education for College and University Students in the Period of New Normal. Education and Vocation, 15, 66-71.

Liu, Y. (2018). Calm Thinking about Hot “AI Education”. Business China, 10, 11-13.

The Ministry of Education (2018). Action Plan for AI Innovation in Colleges and Universities.

Wang, T. M., \& Tao, Y. (2018). Thinking and Suggestions for AI Robot + AI Innovation and Entrepreneurship. Science \& Technology Review, 17, 21-23.

Xie, H. P. (2017). Comprehensively Deepening Education and Teaching Reform Oriented by Innovation and Entrepreneurship Education. China Higher Education Research, 3, $1-5$.

Zhou, N., Gao, Z. F., \& Xu, H. (2018). Framework and Integration of Innovation \& Entrepreneurship Education and Construction of New Engineering Courses in Institutions of Higher Learning. Journal of Hebei Agricultural University, 40, 52. 